Original Article

\title{
The effects of stair gait training using proprioceptive neuromuscular facilitation on stroke patients' dynamic balance ability
}

\author{
KyoChul Seo, PhD ${ }^{1)}$, Seung Hwan Park, PhD²*, KwangYong Park, MS ${ }^{3)}$ \\ 1) Department of Physical Therapy, Korea Nazarene University, Republic of Korea \\ 2) Department of Medical Technology, Eulji University: 553 Sansungdaro Sujung-gu, Sungnam city, \\ GyoungGi-do 461-713, Republic of Korea \\ 3) Department of Rehabilitation Technology, Korea Nazarene University, Republic of Korea
}

\begin{abstract}
Purpose] This study aims to examine stroke patients' changes in dynamic balance ability through stair gait training where in proprioceptive neuromuscular facilitation (PNF) was applied. [Subjects and Methods] In total 30 stroke patients participated in this experiment and were randomly and equally allocated to an experimental group and a control group. The experimental group received exercise treatment for $30 \mathrm{~min}$ and stair gait training where in PNF was applied for $30 \mathrm{~min}$ and the control group received exercise treatment for $30 \mathrm{~min}$ and ground gait training where in PNF was applied for $30 \mathrm{~min}$. For the four weeks of the experiment, each group received training three times per week, for 30 min each time. Berg Balance Scale (BBS) values were measured and a time up and go (TUG) test and a functional reach test (FRT) were performed for a comparison before and after the experiment. [Results] According to the result of the stroke patients' balance performance through stair gait training, the BBS and FRT results significantly increased and the TUG test result significantly decreased in the experimental group. On the contrary, BBS and FRT results did not significantly increase and the TUG test result did not significantly decrease in the control group. According to the result of comparing differences between before and after training in each group, there was a significant change in the BBS result of the experimental group only. [Conclusions] In conclusion, the gait training group to which PNF was applied saw improvements in their balance ability, and a good result is expected when neurological disease patients receive stair gait training applying PNF.

Key words: Proprioceptive neuromuscular facilitation, Stroke, Balance ability
\end{abstract}

(This article was submitted Dec. 5, 2014, and was accepted Jan. 17, 2015)

\section{INTRODUCTION}

As post- injury symptoms, stroke patients have difficulty with balance and postural adjustments, and due to an asymmetric posture and decreases in body balance and the ability to move weight, their postural sway increases and the center of gravity is moved to the non-paretic lower limb ${ }^{1)}$. Balance ability in patients with hemiplegia resulting from a stroke is the most important element in their family members and in themselves, as well as the most important long-term goal in rehabilitation ${ }^{2)}$.

As an active treatment program for stroke patients' functional recovery, stair gait training is applied. Differing from a horizontal gait on the ground, in stair gait training one foot moves the center of gravity in the forward and vertical directions at the same time; therefore, stair gait training re*Corresponding author. Seung Hwan Park (E-mail:
pasuhwa@eulji.ac.kr)

(C)2015 The Society of Physical Therapy Science. Published by IPEC Inc. This is an open-access article distributed under the terms of the Creative Commons Attribution Non-Commercial No Derivatives (by-ncnd) License $<$ http://creativecommons.org/licenses/by-nc-nd/3.0/>. quires more lower limb muscle strength and adjustment ability than ground gait training ${ }^{3)}$. As Christina and Cavanah ${ }^{4)}$ mentioned, physical ability is required more during stair gait than during ground gait training, because balance ability of the trunk and muscle strength of the lower limbs are needed. Stair gait training is an essential element for independent activities of daily living and performing stair gait training may achieve qualitative improvements in independent and social life activities, and is the most important movement training program among treatment processes for hemiplegic patients who are recovering their lower limb functions ${ }^{5}$. Accordingly, stair gait training in the clinical field is an essential exercise process applied to stroke patients who will be discharged from the hospital ${ }^{6}$.

As a method to improve stroke patients' balance ability, there is proprioceptive neuromuscular facilitation ${ }^{7)}$, and this technique stimulates proprioceptors within the muscles and tendons, thereby improving their functions and increasing muscle strength, flexibility, balance ${ }^{8)}$, and coordination, effectively maximizing responses of the motor units. Based on such theoretical grounds, this study intends to examine the effects of stair gait training, to which a PNF technique effective for improving muscle strength necessary for independent gait and retraining muscles was applied, on the balance 
ability of hemiplegic patients, as well as to provide objective data on stroke patients' balance ability through training them in the clinical field.

\section{SUBJECTS AND METHODS}

This study was conducted in K Hospital located in Daegu Metropolitan City from April 25 to May 22, 2014. The criteria for inclusion were: chronic stroke patients whose onset of a stroke occurred six months or longer before and who had been diagnosed with a stroke caused by cerebral hemorrhage using magnetic resonance imaging or computed tomography; who were able to maintain an independent standing posture for $30 \mathrm{~s}$ or longer; who were able to walk for $30 \mathrm{~m}$ or longer alone indoors; who were able to cognitively communicate to understand a therapist's oral directions; and who did not use assisting devices or receive drug therapy through internal medicine to alleviate spasticity. They voluntarily consented to the content and purpose of this study, which was approved by the University institutional review board and was conducted in accordance with the ethical standards of the Declaration of Helsinki. The total number of subjects was 30 and they were randomly and equally assigned to a control group and a stair gait group. The general characteristics of the subjects are summarized in Table 1.

Each group received the intervention three times per week, for four weeks. Prior to the experiment, a physical therapist whose clinical experience was one year or longer applied exercise treatments such as a muscle strengthening exercise, a range of motion (ROM) exercise, and an extension exercise, to all the subjects. Then, the control group traveled back and forth $10 \mathrm{~m}$ on the ground and received gait pattern training through PNF by the physical therapist. The experimenters flexed the subjects' paretic-side knee joints, and at the same time, they adducted and externally rotated the subjects' hip joints while holding the ankles of the subjects and instructing them to "raise your ankle; raise. And flex your knee and leg diagonally". When the lower limb of the paretic side reached the end of the ROM, the experimenters placed one hand on the lateral surface of the knee joint and the other hand on the medial part of the foot top and provided resistance to the opposite side of the subjects' ROM provide proper resistance ${ }^{9,10)}$. During the training, when a patient had acute fatigue, respiratory problems, or dizziness, the training was stopped immediately. To respond to a safety accident like a fall, careful observations and assistance were allowed $^{11,12)}$.

The experimental group received training on wooden stairs with a width of $0.8 \mathrm{~m}$, a stepping plane of $28 \mathrm{~cm}$, and a height of $10 \mathrm{~cm}$. Before the experiment, the researcher sufficiently explained this study to the subjects and obtained consent from them. The experimental group stood in front of stairs for training in a laboratory and received lower limb pattern training for $30 \mathrm{~min}$ and stair gait-training. Standing in front of a gait training device, the subjects received gait pattern training of PNF from the therapist. During the training, when a patient had acute fatigue, respiratory problems, or dizziness, the training was stopped immediately. To respond to a safety accident like a fall, careful observation and assistance were allowed.
Table 1. General characteristics of the subjects

\begin{tabular}{lcc}
\hline & CG & EG \\
\hline Gender (M/F) & $5 / 5$ & $6 / 4$ \\
Age (yr) & $59.5 \pm 7.4$ & $59.4 \pm 10.8$ \\
Height (cm) & $165.5 \pm 5.9$ & $165.1 \pm 4.6$ \\
Weight (kg) & $61.6 \pm 3.6$ & $58.6 \pm 6.9$ \\
Paretic side (R/L) & $5 / 5$ & $6 / 4$ \\
Onset duration (mon) & $29.2 \pm 15.9$ & $34.4 \pm 27.0$ \\
\hline
\end{tabular}

Values are means $\pm \mathrm{SD}$, EG: experimantal group; CG: control group

The Berg Balance Scale (BBS) is largely used to evaluate the balance of elderly people with a high rate of falls and patients with a neurological disease, and it is composed of applied activities of daily living. It is a functional test considering three aspects; postural maintenance, postural adjustments by voluntary movement, and responses to external agitation, and it may simply evaluate balance within a short time ${ }^{13)}$. This measurement tool's intrarater reliability and interrater reliability are $\mathrm{r}=0.99$ and $\mathrm{r}=0.9$, respectively, and they have high reliability and internal validity to evaluate balance ${ }^{14}$. The BBS test items were divided into sitting, standing, and postural changes. The item of sitting included sitting without support. Second, the item of standing included standing without support, standing with eyes closed, standing putting feet together, standing with one leg, looking back, grabbing an object from the floor, standing with one foot in front of the other foot, and extending the arms while flexing the body, Finally the item of postural changes included standing after sitting, sitting after standing, movement, rotating 360 degrees, and putting one foot one after another on a foothold (a total of 14 sub-items). The score of each sub-item ranges from zero to four points with the total score at 56 points. When a subject performed a sub-item independently or within a determined time, four points were given $^{14)}$

A timed up and go (TUG) test is used to evaluate functional motions including balance and gait abilities. It can swiftly evaluate functional movements composed of standing, walking $3 \mathrm{~m}$, and sitting again after coming back. The measuring method is used to record the time required for a subject to sit on a chair whose height is $50 \mathrm{~cm}$, standing, walking $3 \mathrm{~m}$ and coming back and sitting down in the chair again at least twice, as well as to record average values. When the time taken was longer than 30 s, the subject was reported to be unable to move outdoors alone because the subject was dependent in basic movement capabilities. The measurement method is not complicated and may be appropriately applied to hemiplegic patients with lower limb disability such as spasticity. The intrarater reliability and interrater reliability of this test were $r=0.99$ and $r=0.98$, respectively, with a high reliability ${ }^{15)}$.

The functional reach test (FRT) is used to measure dynamic balance ability and to evaluate the limit of stability. This method was used to measure a subject to instructed to stand a flat floor at a $10 \mathrm{~cm}$ distance from a wall, spread the legs shoulder width apart, stand comfortably, clench the 
Table 2. Comparison of the gait ability of the experimental and control subjects

\begin{tabular}{lcccc}
\hline & \multicolumn{2}{c}{ CG $(\mathrm{n}=10)$} & \multicolumn{2}{c}{ EG $(\mathrm{n}=10)$} \\
\cline { 2 - 5 } & Pretest & Posttest & Pretest & Posttest \\
\hline BBS (score) & $23.9 \pm 3.9$ & $25.0 \pm 1.2$ & $26.6 \pm 6.8$ & $34.3 \pm 12.3^{*_{\mathrm{a}}}$ \\
TUG (sec) & $55.9 \pm 7.8$ & $53.9 \pm 2.4$ & $53.5 \pm 13.6$ & $43.5 \pm 13.1^{*_{\mathrm{a}}}$ \\
FRT $(\mathrm{cm})$ & $5.0 \pm 2.5$ & $5.7 \pm 0.3$ & $7.7 \pm 1.5$ & $9.2 \pm 4.3^{*}$ \\
\hline
\end{tabular}

Mean \pm SE, ${ }^{*}$ Significant difference from pre-test, $\mathrm{p}<0.05$; ${ }^{\text {a }}$ significant difference in gains between the two groups, $\mathrm{p}<0.05$; EG: experimental group; CG: control group; BBS: Berg Balance Scale; TUG: Timed Up and Go; FRT: Functional Reaching Test

fists, extend the elbows, flex the shoulder at 90 degrees, move the body forward as maximally as possible using only the ankle joint, and extend the body parallel as maximally as possible. Then the distance to the tip of the middle finger was measured. Test-retest reliability and inter-rater reliability are high at $\mathrm{r}=0.89$ and $\mathrm{r}=0.98$, respectively ${ }^{16)}$.

For an analysis of the data of this study, SPSS 17.0 for Windows was used and a paired t-test was conducted to verify each group's significance before and after the experiment. An independent t-test was carried out to compare differences between before and after the experiment. A statistical significance level was set at $\alpha=0.05$.

\section{RESULTS}

According to the result of examining stroke patients' balance performance ability through gait training, the experimental groups' BBS and FRT results significantly increased $(\mathrm{p}<0.05)$ and its TUG test result significantly decreased $(p<0.05)$. Nonetheless, the control group's BBS and FRT did not significantly increase $(\mathrm{p}>0.05)$ and its TUG did not significantly decrease $(\mathrm{p}>0.05)$. According to the result of comparing differences between the two groups after the intervention, the BBS and TUG test results were significantly different $(\mathrm{p}<0.05)$ (Table 2).

\section{DISCUSSION}

Patients with hemiplegia caused by a brain injury experience considerable difficulty with gait due to abnormal muscle contraction timing, the weakening of muscle tension, and unstable standing balance maintenance ${ }^{17}$. Among exercise treatment methods to complement such functional problems, a facilitation method can activate the mechanism of neuroplasticity, and; it was proven as a treatment intervention through diverse research. Westerholt ${ }^{18}$ ) noted facilitation occurred when pressure was applied against the direction of muscle contraction and when stimulation was applied to the skin and pressure sensations. Horst ${ }^{19)}$ observed that an improvement in independent activities of daily living is the most important goal of treatment and to achieve this goal, all usable information should be mobilized in combination, as well as visual and auditory information. Dietz ${ }^{20)}$ reported that appropriate resistance with a gross muscle exercise of three-dimensional motions by a PNF pattern combination strengthened static and dynamic contractions. Based on such research, given that a PNF pattern aimed at inducing positive movements in hemiplegic patients will provide them with functional recovery in terms of gait and kinematics, the present study applied stair gait training with PNF to stroke patients for four weeks and intended to examine changes in balance ability after the exercise.

According to the result of examining balance performance ability through gait training, the BBS test result significantly increased in both groups and the TUG test result significantly decreased in both groups. Nonetheless, the FRT result significantly increased only in the experimental group. In the test, regarding differences between the two groups after the intervention, only BBS significantly differed. This is considered because movements were triggered more greatly during stair gait than during ground gait training, stimulating proprioceptive functions of the ankle joints. In addition, when the lower limb joints were flexed for support on the stairs, vertical movements of the body in the forward and upward directions occurred, maintaining the force generated in the rear lower limb and requiring more balance ability for body alignment.

In an experiment on chronic hemiplegic patients who were divided into a proprioceptive group and a visual feedback group, the BBS score of the proprioceptive group increased from 45.69 points to 51.54 points $^{21)}$. Bohannon and $\mathrm{Lu}-$ sardi $^{22)}$ reported the BBS score was $54.6 \pm 0.5$ points in those aged between 60 and 69 years and $51.6 \pm 2.6$ points in those aged between 70 and 79 years, as well as acknowledged those with 41 to 56 points have a low risk of a fall while those whose score was 20 points or lower had a very high risk of a fall. Hwang ${ }^{23)}$ studied gaits of chronic hemiplegic patients and divided the subjects into a proprioceptive group and a visual feedback group, as well as reported the BBS and TUG tests result significantly differed in the proprioceptive group after the intervention. Geiger et al. ${ }^{21)}$ divided chronic hemiplegic patients into a proprioceptive group and a control group and observed the TUG test result decreased from $23.08 \mathrm{~s}$ to $14.62 \mathrm{~s}$ in the proprioceptive group. Lee et al. ${ }^{24)}$ noted an experiment was conducted for four weeks, with the elastic band group based on a PNF lower limb pattern and a control group as the subjects, and the FRT value of the PNF group was statistically significantly changed, which is consistent with the present study result.

In the present study, hemiplegic patients who received stair gait training with a PNF technique saw effective improvements in balance, and the present study result will provide important data that a PNF technique may provide balance recovery through rehabilitation training owing to manual therapeutic effect based on Dietz's ${ }^{20)}$ grounds. In the future, if gait training through diverse double tasks is con- 
ducted as well as mere stair training, lower limb gait training using PNF pattern will result in a better functional recovery for patients' balance ability.

\section{ACKNOWLEDGEMENT}

This Research was supported by the Korean Nazarene University Research Grants 2015.

\section{REFERENCES}

1) Eng JJ, Chu KS: Reliability and comparison of weight-bearing ability during standing tasks for individuals with chronic stroke. Arch Phys Med Rehabil, 2002, 83: 1138-1144. [Medline] [CrossRef]

2) Eich $\mathrm{HJ}$, Mach $\mathrm{H}$, Werner $\mathrm{C}$, et al.: Aerobic treadmill plus Bobath walking training improves walking in subacute stroke: a randomized controlled trial. Clin Rehabil, 2004, 18: 640-651. [Medline] [CrossRef]

3) Riener R, Rabuffetti M, Frigo C: Stair ascent and descent at different inclinations. Gait Posture, 2002, 15: 32-44. [Medline] [CrossRef]

4) Christina KA, Cavanagh PR: Ground reaction forces and frictional demands during stair descent: effects of age and illumination. Gait Posture, 2002, 15: 153-158. [Medline] [CrossRef]

5) Kim YS: Muscle activation patterns of stair gait in hemiparetic patients using surface electromyography. J Adapted Phys Act, 2006, 14: 3-4.

6) Bassett DR, Vachon JA, Kirkland AO, et al.: Energy cost of stair climb ing and descending on the college alumnus questionnaire. Med Sci Sports Exerc, 1997, 29: 1250-1254. [Medline] [CrossRef]

7) Ferber R, Osternig L, Gravelle D: Effect of PNF stretch techniques on knee flexor muscle EMG activity in older adults. J Electromyogr Kinesiol, 2002, 12: 391-397. [Medline] [CrossRef]

8) Klein DA, William JS, Wayne TP: PNF training and physical function in assisted-living older adults. J Aging Phys Act, 2002, 41: 476-488.

9) Bae SS: Gait training strategy by CPG in PNF with brain injured patients. J Kor Soc Phys Ther, 2005, 17: 13-24.
10) Ku BO, Kwun MJ, Kim KT, et al.: Treatment of neurological and muscle and joint proprioceptive neuromuscular facilitation: evidence-based diagnosis and intervention. DaiHak Public, 2009, 385-389.

11) Lee J, Seo K: The effects of stair walking training on the balance ability of chronic stroke patients. J Phys Ther Sci, 2014, 26: 517-520. [Medline] [CrossRef]

12) Seo KC, Lee JH, Lee SY: Impact of PNF-based walking exercise on a ramp on gait performance of stroke patients. J Phys Ther Sci, 2012, 24: $1243-$ 1246. [CrossRef]

13) Berg K: Balance and its measure in elderly: a review. Physiother Can, 1989, 41: 240-246. [CrossRef]

14) Jonsdottir J, Cattaneo D: Reliability and validity of the dynamic gait index in persons with chronic stroke. Arch Phys Med Rehabil, 2007, 88: 14101415. [Medline] [CrossRef]

15) Ng SS, Hui-Chan CW: The timed up \& go test: its reliability and association with lower-limb impairments and locomotor capacities in people with chronic stroke. Arch Phys Med Rehabil, 2005, 86: 1641-1647. [Medline] [CrossRef]

16) Duncan PW, Weiner DK, Chandler J, et al.: Functional reach: a new clinical measure of balance. J Gerontol, 1990, 45: M192-M197. [Medline] [CrossRef]

17) Patterson KK, Parafianowicz I, Danells CJ, et al.: Gait asymmetry in community-ambulating stroke survivors. Arch Phys Med Rehabil, 2008, 89: 304-310. [Medline] [CrossRef]

18) Westerholt F: International PNF Basic Course Book. Daejeon, 2005.

19) Horst R: International PNF Basic Course Book. Seoul, 2006.

20) Dietz B: International PNF Basic Course Book. Gwangjoo, 2006

21) Geiger RA, Allen JB, O'Keefe J, et al.: Balance and mobility following stroke: effects of physical therapy interventions with and without biofeedback/forceplate training. Phys Ther, 2001, 81: 995-1005. [Medline]

22) Bohannon RW, Lusardi MM: Getting up from the floor. Determinants and techniques among healthy older adults. Physiother Theory Pract, 2004, 20: 233-241. [CrossRef]

23) Hwang BY: Effects of proprioceptive control on the balance in patients with chronic hemiplegi. KNUTPT, 2004, 11: 69-74.

24) Lee HS, An YH, K HJ, et al.: Effects of elastic band exercise based of PNF $\mathrm{L} / \mathrm{E}$ pattern on the balance in the elderly people. The Journal of Korean Society of Physical Therapy, 2005, 17: 61-70. 